\section{«-Eu que fiz!» A produção de curtas-metragens como estratégia tecnológica de autoria, aprendizagem e inclusão (maio 2016)}

Recibido: 15 Ago 2016 - Revisado: 30 Sep 2016

Aceptado: 30 Oct 2016 - Publicado: 30 Dic 2016

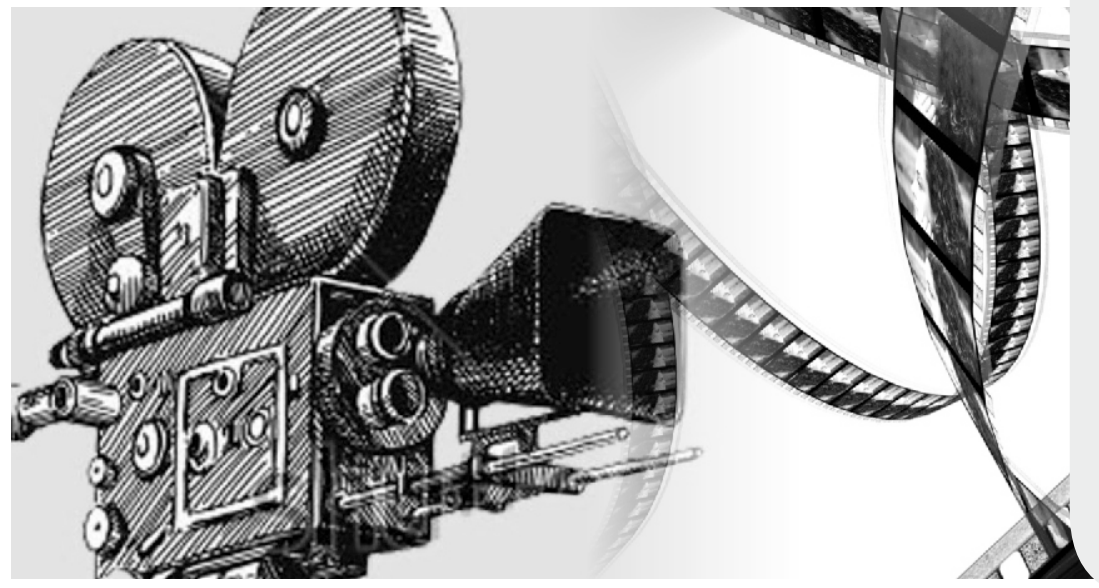

\section{S. Lindenmeyer}

Simone Lindenmeyer, Pedagoga, Pós-Graduada em Psicopedagogia Institucional e Atendimento Educacional Especializado pela Universidade Federal do Ceará; membro da ATRIUM - Grupo de Pesquisas, Comunicação Aumentativa e Alternativa, Rede Municipal de Ensino de Novo Hamburgo, Brasil. Email:simone321@gmail.com

\section{Schmidt}

Madebe Schmidt, Pedagoga, Pós-Graduada em Pelotas/RS e em Autismo Grave: inclusão social de Pelotas/RS e em Autismo Grave: inclusão social e escolar (EST/São Leopoldo); membro da ATRIUM - Grupo de Rede Municipal de Ensino de Novo Hamburgo, Brasil. Email: madebeteatro@gmail.com

\section{F. Matias}

Flávia Matias, Terapeuta Ocupacional formada pela Universidade Federal de Minas Gerais, Pós-Graduad em Educação Inclusiva na Universidade Federal de São Carlos/SP e em Autismo Grave: inclusão social e escolar (EST/São Leopoldo); Terapeuta Ocupacional, membro da ATRIUM - Grupo de Pesquisas, Comunicação Aumentativa e Alternativa, Rede Municipal de Ensino de Sapiranga, Brasil. Email:flaviabubu@gmail.com

\section{R. Bez}

Maria Rosangela Bez, Doutora, Programa de PósGraduação em Informática, Educacão da Universidade Federal do Rio Grande do Sul (UFRGS), Brasil, mesma

instituicão que esta cursando o Pós Doutorado. Email: bezrosangela@gmail.com

Resumo: Este relato aborda uma prática pedagógica que utilizou a produção de curtas-metragens como estratégia de autoria, aprendizagem e inclusão. O projeto ocorreu no ano de dois mil e quinze, com dez alunos do quarto e quinto anos que frequentavam o chamado Laboratório de Aprendizagem e também alunos com deficiência, que faziam e fazem parte ainda hoje do Atendimento Educacional Especializado de uma escola da cidade de Novo Hamburgo, região metropolitana de Porto Alegre, Rio Grande do Sul/Brasil. Propõe uma reflexão e traz visibilidade às diferenças daqueles que chamamos de alunos com dificuldades de aprendizagem e dos alunos com deficiência. Existem diferentes maneiras de se olhar as diferenças que emergem no ambiente escolar. A proposta é de que o leitor experimente contemplar as potencialidades desses sujeitos e não as suas dificuldades ou a sua deficiência; que coloque as lentes da criação, da autoria e do prazer que se constrói e circula a nível das individualidades como da coletividade a partir deste artefato tecnológico-criativo. A produção de curtas-metragens surge como uma ferramenta para demonstrar como o protagonismo do aluno pode ser fortalecido por meio da autoria.

Index Terms: Curtas-metragens, tecnologia, inclusão, aprendizagem, autoria.

Abstract: This report addresses the issue of a pedagogical practice that used the production of short films as a strategy of own authorship, learning and social inclusion. The project it ocurred in the year two thousand and fifteen, with ten fourth and fifth year students attending the so-called "Learning Laboratory" and also students with mental desabilities, who were and still are part of the Specialized Educacional Service of a school in the city of Novo Hamburgo, metropolitan region of Porto Alegre, Rio Grande do Sul/Brazil. It proposes a reflection and brings visibility to the differences of those we call students with "learning difficulties" and studens with menta desabilities. There are different ways of looking at the differences that emerge in the school environment. The proposal is that the reader try to contemplate the potentialities oh these subjects and not their dificulties or their deficiency. That puts the "lens of creation", of own authorship and of the pleasure that is built and circulates at the level of the individualities, as of the collective from this technological-creative artifact. The production of short films appears as a toolto demonstratehow the protagonism of the student can be strengthened trought the own authorship.

Index Terms: Short films, tecnology, social inclusion, learning, own authorship. 


\section{INTRODUÇÃO}

Pensar, planejar passos e efetivar «a produção de curtas-metragens como estratégia tecnológica de autoria, aprendizagem e inclusão», utilizando, portanto, o dispositivo da cinematografia foi desafiador, porém, impulsionou ao desejo de poder contá-lo e compartilhá-lo tamanhos os retornos e outras reflexões que se desdobraram ao longo do caminho.

Iniciando a 'trama' desta experiência é preciso que situemos o seu contexto. Esta proposta de intervenção/ação foi desenvolvida e efetivada pelas pesquisadoras no decorrer dos períodos semanais do Atendimento Educacional Especializado e do Laboratório de Aprendizagem de uma escola pública municipal instalada num bairro da cidade de Novo Hamburgo, Rio Grande do Sul, Brasil, constituído populacionalmente, em sua maioria, por trabalhadores das indústrias de calçados. Foi realizado no ano de dois mil e quinze, com dez alunos do quarto e quinto anos. Destes alunos incluídos, dois frequentavam o Atendimento Educacional Especializado e oito frequentavam o Laboratório de Aprendizagem no turno contrário ao de estudo. No Atendimento Educacional Especializado os alunos eram/são atendidos individualmente e no Laboratório de Aprendizagem, em duplas, trios ou grupos, de acordo com as suas especificidades.

Caracterizando, o trabalho desenvolvido no Atendimento Educacional Especializado caracterizase por acolher e atender alunos com deficiência (incluindo Transtorno Global do Desenvolvimento) e ou superdotação ao longo do processo educativo, constituindo-se num serviço disponibilizado pela federação e instituído também nesta rede municipal para oferecer o suporte necessário às suas necessidades educacionais favorecendo o seu acesso ao conhecimento. É uma forma de garantir que sejam reconhecidas e atendidas as particularidades de cada aluno. Já o trabalho desenvolvido no Laboratório de
Aprendizagem parte das necessidades e dificuldades específicas de cada aluno, oferecendo subsídios pedagógicos e estratégias diferenciadas, contribuindo para a aprendizagem dos conhecimentos/conteúdos, poderíamos dizer, formais da classe comum. Quanto às semelhanças, tanto um como outro oportunizam a autonomia, a independência, e a valorização das ideias dos alunos, desafiando-os a empreenderem o planejamento de suas atividades. São espaços de apoio, estímulo ao crescimento e desenvolvimento de potencialidades.

Pensando nos sujeitos desse projeto, muitas vezes rotulados de «alunos que não aprendem», "alunos diferentes dos demais», "os atrasados», "os que não acompanham a turma» percebemos que estes rótulos Ihes imprimem uma espécie de espelho (o olhar de si mesmos) que acaba Ihes conferindo um modo de agir e de 'ser' dentro e fora da escola. Produz inclusive atitudes, os molda, os transforma para 'menos'. O discurso dos outros os constituem.

Tinha-se por objetivo realizar uma intervenção, efetivar uma proposta que interferisse nestes 'moldes' e que pudesse auxiliar no que se refere a uma outra direção na formação da identidade social destes sujeitos, por isso a produção de curtas-metragens surgiu como uma ferramenta para demonstrar como o protagonismo do aluno pode ser fortalecido por meio da autoria.

Para embasar esta pesquisa se utilizou do referencial teórico focado em [1] no que diz respeito a abertura de possibilidades para alavancar os alunos ao protagonismo como autores de seu desenvolvimento. Freire, P. (2003) e Pereira, J. \& Janhke, G. (2012) no que tange a utilização dos recursos audiovisuais no contexto escolar.

Para sanar os objetivos e metas propostas deste trabalho, o mesmo foi dividido em introdução e capítulos. O primeiro capítulo, intitulado «Aprofundamentos Teóricos Dialogados para esta 
Intervenção», apresenta o referencial teórico; o segundo capítulo traz a «Metodologia»; já o terceiro capítulo, refere-se ao "Desenvolvimento dos Curtas Metragens" e todo seu processo de elaboração e posterior apresentação a comunidade escolar; finalizando-se com as «Considerações Finais».

\section{APROFUNDAMENTOS TEÓRICOS DIALOGADOS PARA ESTA INTERVENÇÃO}

A necessidade dos educadores criarem as possibilidades para a produção ou para a construção do conhecimento pelos alunos (as), num processo em que o professor e o aluno não se reduzem à condição de objeto um do outro, sugere que «(...) ensinar não é transferir conhecimento, mas criar as possibilidades para sua própria produção ou a sua construção». [1].

Reflete-se sobre o olhar que se tem sobre as diferenças de alunos com dificuldades e ou com deficiência. Percebe-se que existem diferentes maneiras de se olhar as diferenças que emergem no ambiente escolar. Nesse contexto, as potencialidades desses sujeitos foram contempladas e não as suas dificuldades. Pensando-se em estratégias que favorecessem a criação, a autoria e a autoafirmação.

Optou-se pois, em consenso, pelo artefato cinematográfico; mais especificamente, na produção de curtas-metragens. Esta estratégia aplicada na escola poderia proporcionar uma mudança que visasse não o acúmulo de informações, mas sim a aprendizagem, possibilitando "um ensino e uma aprendizagem mais criativa, autônoma, colaborativa e interativa (FARIA 2001, p.64)». Desta forma, o processo pedagógico concreto e acessível ao professor seria possível, desde que, o mesmo, tivesse equipamentos e softwares necessários e soubesse utilizar as ferramentas tecnológicas para elaboração dos 'curtas'.

Além de se pensar nesta intervenção pedagógica baseada numa estratégia tecnológica de autoria, reflete-se sobre as metas/objetivos, quais sejam:

- Proporcionar dispositivos e momentos onde este grupo de alunos pudessem melhorar sua autonomia e autoestima;

- Promover atividades e ações que desenvolvessem a comunicação oral, a leitura e escrita;

- Oferecer recursos e ferramentas digitais e tecnológicas para melhorar o desempenho no processo ensino-aprendizagem;

- Promover momentos e vivências que contemplem o raciocínio lógico (coerência e pertencimento) da ideia de cada equipe na produção do seu 'curta' bem como a sequência da história nas produções textuais;

- Possibilitar o desenvolvimento de habilidades e competências físicas, mentais e sociais, com a finalidade de otimizar sua independência nos cuidados pessoais e nas tarefas de vida diária;

- Propor atividades que aprimorassem a capacidade de concentração do aluno.

Acredita-se em uma educação libertadora que proporciona ao indivíduo condições para atuar na transformação de si mesmo e da realidade. Dentro dessa concepção de educação libertadora, emergem práticas e ações educativas centradas no diálogo e na participação dos sujeitos envolvidos. Sobre essas ações, a tecnologia pode ser uma aliada e a produção de Curta Metragem uma ferramenta da prática pedagógica, que contribui para a aprendizagem, a autoria e favorece também a inclusão.

Professor, só tome cuidado para não pedagogizar o meio audiovisual pois se isto acontecer é a forma de não utilizar o que de melhor ela apresenta, o sonhar, sentir. Em muitos momentos a escola deveria apenas apresentar, deixar a curiosidade do aluno construir o conhecimento e pesquisar sobre isto. E a vantagem de se produzir vídeo é justamente esta, ele é um produto que aceita a autoria de um coletivo, incentivando a necessidade de compartilhar sentidos, e também pode contribuir para a exploração da linguagem escrita durante 
todo o processo, principalmente o de pré produção. Nosso foco não é no vídeo como produto final, mas no processo que o aluno leva para realizar a obra audiovisual. (Freire, 2003)

Ao produzir-se um 'curta' na escola se desafiaria os alunos a 'aprenderem com mais facilidade', pois se apropriariam de recursos cognitivos e tecnológicos no processo de criação e execução. Interagiriam com imagens, sons, e produções de textos de diversos gêneros.

Complementando essas ideias foi discutido sobre o que relata (Pereira \& Janhke, 2012), quando diz que o vídeo é:

sensorial, visual, linguagem falada, linguagem musical e escrita. Linguagens que interagem superpostas, interligadas, somadas, não separadas. Daí a sua força. Nos atingem por todos os sentidos e de todas as maneiras. O vídeo nos seduz, informa, entretém, projeta em outras realidades (no imaginário) em outros tempos $e$ espaços. O vídeo combina a comunicação sensorial-cinestésica, com a audiovisual, a intuição com a lógica, a emoção com a razão. Combina, mas começa pelo sensorial, pelo emocional e pelo intuitivo, para atingir posteriormente o racional.

\section{METODOLOGIA}

O percurso metodológico deste estudo teve como base a pesquisa qualitativa. Segundo (Moran, 1993), esse tipo de pesquisa, trabalha com o universo de significados, motivos, aspirações, crenças, valores, atitudes, o que corresponde a um espaço mais profundo das relações dos processos e dos fenômenos que não podem ser reduzidos à operacionalização de variáveis. Envolve ainda, a imersão do pesquisador em um cenário social em que «tem lugar o fenômeno estudado em todo o conjunto de elementos que o constitui, e que, por usa vez, está constituído por ele». (Minayo de S. O, M. C. S., 2010)

A forma de estudo de caso foi escolhida dentro do paradigma qualitativo, sendo adotado por ser «uma investigação empírica que investiga um fenômeno contemporâneo dentro de seu contexto da vida real, especialmente quando os limites entre o fenômeno e o contexto não estão claramente definidos» (González, 2005). Com relação à técnica de pesquisa, utilizou-se a observação participante na qual o pesquisador participa ativamente das atividades em conjunto com o observado.

O público-alvo foram dez alunos do quarto e quinto anos do Ensino Fundamental. Destes alunos incluídos, dois frequentavam o Atendimento Educacional Especializado e oito frequentavam o Laboratório de Aprendizagem no turno contrário ao de estudo. O contexto desta pesquisa foi em uma escola da rede municipal de ensino.

Para o desenvolvimento dos 'curtas' foi planejado um roteiro de ações onde os encontros obedeceriam a um cronograma dividido em vinte etapas de produção e mais dois dias; um previsto para a participação da IV Mostra Experimental de Curtas-Metragens «Curta Inclusão e Diversidade», promovida pela Secretaria Municipal de Educação e outro para a realização e finalização desta intervenção na própria escola, que se constituiu numa Mostra de Curtas Metragens, que daria visibilidade às produções realizadas pelos alunos.

Os encontros tinham a duração de uma hora por semana, portanto, as produções duraram mais ou menos quatro meses e vinte dias (ocorreram nos meses de abril a setembro). Os vídeos produzidos utilizaram diferentes técnicas e uma delas era a realização de quatro curtas em 'Stop Motion': técnica de animação com recursos de filmadora, máquina fotográfica e do computador onde são utilizados 
modelos reais de diversos materiais que são fotografados quadro a quadro.

Para a realização desta intervenção, utilizou-se máquina digital, tripé, um computador e um notebook com acesso à internet, com os seguintes softwares instalados: Windows Movie Maker, Wonder Share Filmora, Formact Factory, Download Helper, For Shared. Além disso, utilizou-se papel, lápis de escrever e de cor e materiais que foram utilizados especificamente nas produções.

\section{DESENVOLVIMENTO DOS CURTAS METRAGENS}

Os primeiros cinco encontros (etapas de um a cinco) foram destinados à elaboração do roteiro, desde a sua criação, passando pela escrita até a correção. Nestes momentos, foi lançada a proposta aos alunos. Fora relatado sobre a importância da sequência de uma história, do roteiro ser bem claro e objetivo e de como essa história poderia virar um filme. Apresentou-se diferentes tipos de produções de curtas-metragens e algumas técnicas que poderiam ser utilizadas como: filmagem direta, Stop Motion, seleção de imagens livres da internet, a fotografia e o ato de fotografar, etc. Os alunos nesta etapa deveriam estar imergidos do desejo de aprender através da técnica de produção, pois é a partir deste momento que já começa o encantamento do autor por sua obra (no caso, os alunos).

Duas das produções foram coletivas. Alguns alunos tiveram dificuldades na correção. Um aluno ainda não estava alfabético, então contribuiu oralmente. Outro aluno tinha dificuldade de segmentar as palavras dentro de uma frase, então precisou de um pouco mais de tempo nessa etapa. Todos tiveram autonomia para escolherem as temáticas dos roteiros. Mesmo as histórias sendo de ficção, a maioria escolheu assuntos ligados aos seus desejos e ao cotidiano, como dois alunos que gostavam de futebol, a menina que gostava de dança, outro que adorava um jogo de videogame, uma que tem um sonho de ser professora e um que fez uma homenagem ao seu cachorro. Uma das produções coletivas foi realizada com massinha de modelar, nesse caso acreditamos que o recurso motivou a criação do roteiro, porque esse material era novidade na sala e estimulou o potencial criativo dos alunos. Assim como um dos filmes que surgiu de uma receita de salada de frutas, que era um desejo de dois alunos de fazerem a receita para degustarem depois. O mais importante dessa fase foi a motivação dos alunos que estavam realmente apaixonados pelas suas histórias. Nesse início, através de filmagens dos momentos de produção debatidos posteriormente no ATRIUM (Grupo de Pesquisa) observou-se que a aprendizagem se tornou uma constante.

Nas próximas fases (etapas seis e sete), os alunos definiram os recursos e materiais, realizaram pesquisas e também planejou-se no ATRIUM, a partir das suas ideias, as sugestões das próximas ações.

Nas etapas seguintes (oito, nove e dez), os alunos partiram para ação. Filmagens, seleção de imagens ou fotografias, dependendo da técnica utilizada. As aprendizagens dessa fase foram variadas, alguns aprenderam como manusear máquina digital, outros a salvar imagens, criar pastas no computador e quem escolheu fazer o filme em Stop Motion, além destas habilidades, exerceu a paciência, pois teve que mexer bem devagar os objetos de cena e fotografar, mexer mais um pouquinho e fotografar, foram mais de mil fotografias por menos de três minutos de filmagem.

Todos demonstraram que a busca pelo resultado final compensava. Para motivá-los, sempre foi mostrado o material coletado, na própria máquina digital ou no visualizador de fotos do computador, acelerando as imagens e fazendo uma projeção de como ficaria. Os 'curtas' foram sendo celebrados com palmas, sorrisos, satisfação de objetivo alcançado em cada etapa.

Já com o material coletado, os alunos começaram a análise do material e iniciaram na edição do filme 
(etapas 11, 12 e 13). Para isso, foram utilizados os softwares Movie Maker e Wondershare Filmora. Nessa etapa, os alunos aprenderam a utilizar recursos básicos de inserir imagens e vídeos. A maioria precisou de ajuda para mexer no tempo de cada imagem ou vídeo. Também utilizou-se os comandos «Ctrl + C» e «Ctrl + V» (ferramenta de copiar e colar no computador) para introduzir os textos. Alguns grupos de alunos colocaram efeitos de transição ou de imagens.

Na fase seguinte (etapas 14, 15 e 16), os alunos pararam um pouco a edição e se dedicaram à trilha sonora. Os alunos utilizaram o 'Youtube' para escolherem as músicas do seu Curta Metragem. Depois utilizamos, no nosso Grupo de Pesquisas o software 'Formact Factory' para transformar os vídeos das músicas em formato Mp3.

Nesta etapa, explicou-se sobre a Lei de Direitos Autorais das músicas para publicações. Como os vídeos não seriam comercializados e, a princípio, seriam utilizados como parte de uma experiência pedagógica na escola, poderíamos utilizar, porém, se fôssemos apresentar em uma mostra ou festival teríamos que modificar a trilha sonora com uma música autoral, livre ou de domínio público.

Foi o que aconteceu com um vídeo que representou a escola na IV Mostra Experimental de CurtasMetragens "Curta Inclusão e Diversidade», promovida pela Secretaria Municipal de Educação do município, que ocorre anualmente. Foi importante deixar que os alunos escolhessem suas trilhas pela questão da identidade que estavam construindo; faz parte da sua 'assinatura' na obra. Voltou-se, então, para a edição dos filmes (etapas 17, 18,19 e 20). Os alunos inseriram as músicas, colocaram os títulos, os créditos e realizaram as narrações. Finalizaram, mudaram letras, enfim, realizaram o acabamento do curta-metragem.
A última etapa ocorreu no mês de novembro, quando houve duas datas de extrema importância e de culminância do trabalho: a participação na IV Mostra Experimental de Curtas-Metragens «Curta Inclusão e Diversidade», promovida pela Secretaria Municipal de Educação de Novo Hamburgo, apresentada dentro de uma sala do cinema da cidade e o "l Curta a Escola», onde foram apresentados todos os 'curtas' produzidos por estes alunos.

Criou-se dentro da escola um espaço temático, com direito a «tapete vermelho» para os autores. Para a mostra, foram convidados familiares, colegas, professores, amigos, funcionários da escola, a Secretaria Municipal de Educação, entre outros.

Os curtas foram exibidos em um telão e posteriormente os autores foram homenageados com uma medalha e certificado de participação. Foi um momento extremamente significativo para os alunos envolvidos, muitos pais se emocionaram ao verem o potencial de seus filhos destacados!

Todos na escola estavam envolvidos com a proposta, acompanhavam de perto o crescimento, envolvimento e a euforia dos alunos. Sempre se compartilhava todas as etapas com os professores, a diretora, a coordenadora pedagógica e os funcionários.

Todos os momentos foram importantes e significativos, não só pelo resultado final, mas sim por todo processo alcançado ao longo do percurso. Percebeu-se no Grupo de Pesquisas ATRIUM (durante a análise do processo criativo nos encontros realizados) um crescimento em todos os sujeitos envolvidos. Se poderia descrever sobre a trajetória de cada um dentro desse projeto, mas o número de caracteres não nos permitiria e talvez as palavras não conseguissem traduzir na íntegra toda a aprendizagem, o envolvimento e o crescimento de 
cada um, pois alguns são um tanto subjetivos. Porém, resumidamente pode-se descrever um dos momentos:

Um dos sujeitos envolvidos é J., uma aluna com deficiência auditiva, que em anos anteriores estava aprendendo libras, mas não se adaptou e através de dois aparelhos auditivos começou a ouvir, porém tinha muita dificuldade de se expressar, interagir e falar com as pessoas. Na hora de narrar seu 'curta', perguntou-se se ela queria que outra pessoa narrasse e ela disse: «-Não! Eu que fiz! Eu vou fazer!». Quando ela terminou a narração foi um misto de encantamento, orgulho e felicidade. Teve até gente que disse que era a primeira vez que ouvia a sua voz.
Depois disso ela não parou mais de falar. Os professores contavam que ela estava participando oralmente das aulas, lendo textos em voz alta, apresentando trabalhos para a turma, enfim melhorou até a interação com os colegas. No Atendimento Educacional Especializado foi continuado esse processo de estimular a fala. Atualmente ela está criando o seu segundo curtametragem, estamos também gravando um clipe onde ela canta!

Na sequencia apresenta-se o processo de construção de dois dos curtas-metragens e uma imagem da apresentação na escola. 


\section{Ingenierías:Hי י}

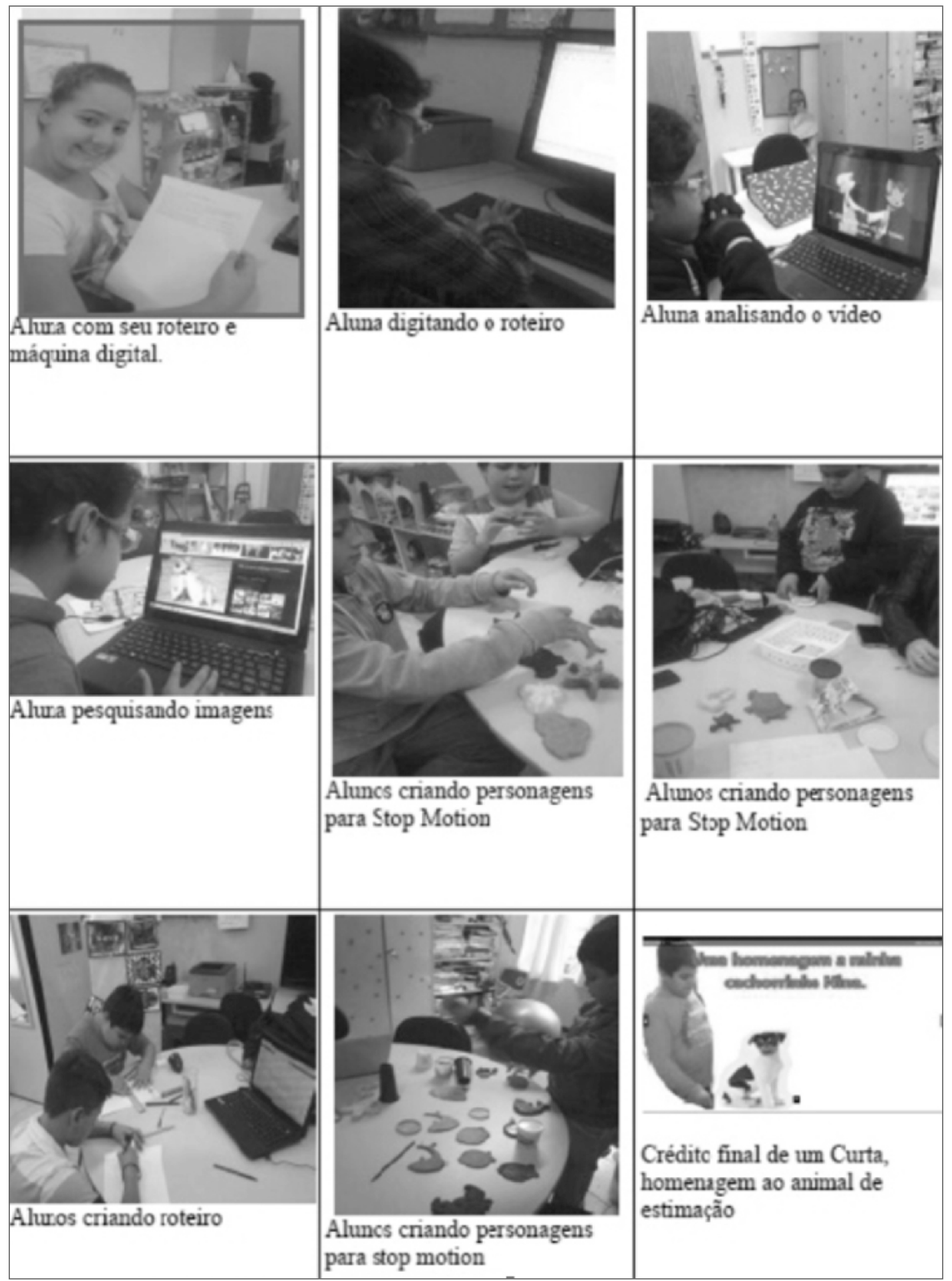

Figura 1. Processo visual de criação de curtas metragens. 


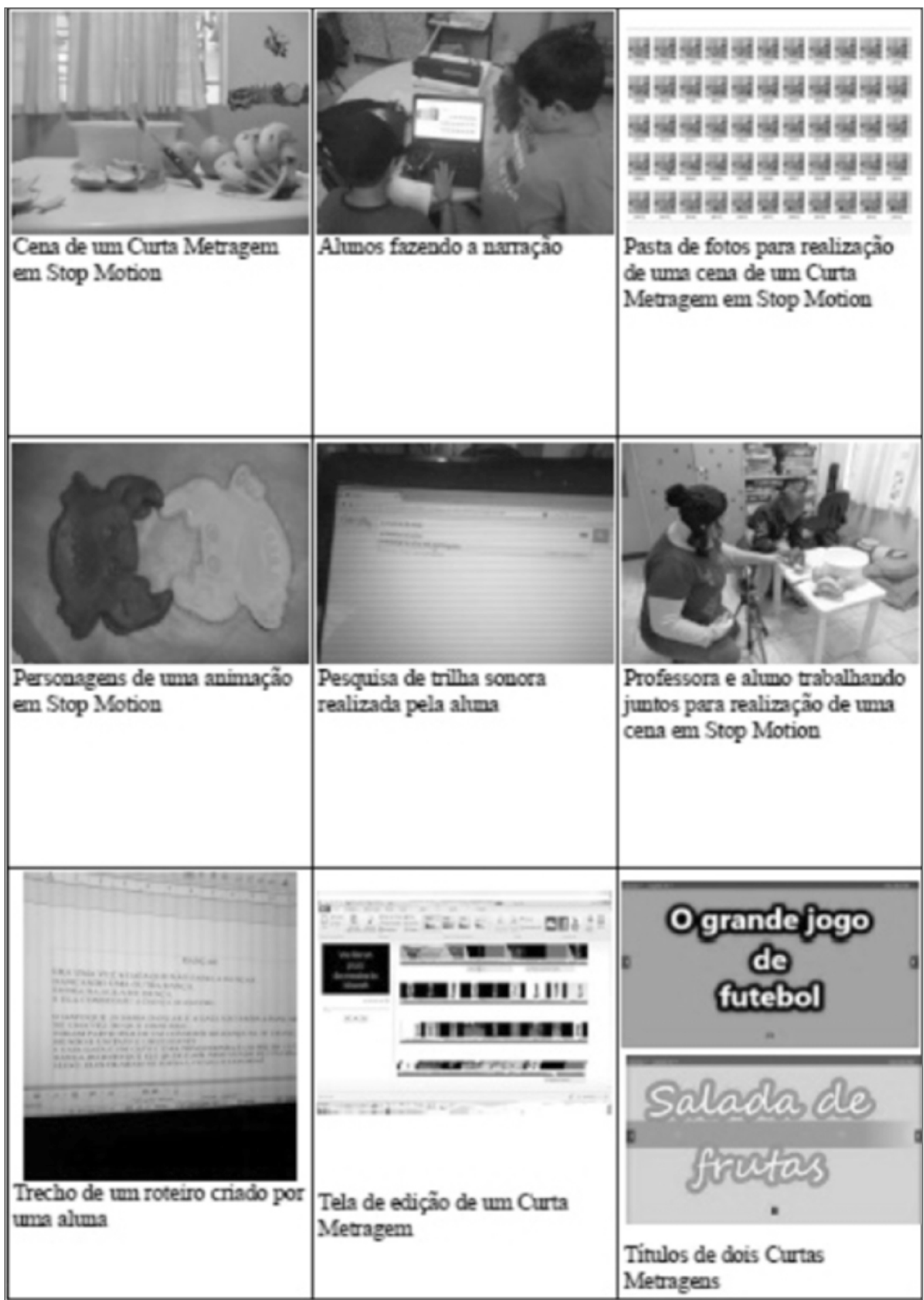

Figura 2. Processo visual de criação de curtas metragens. 


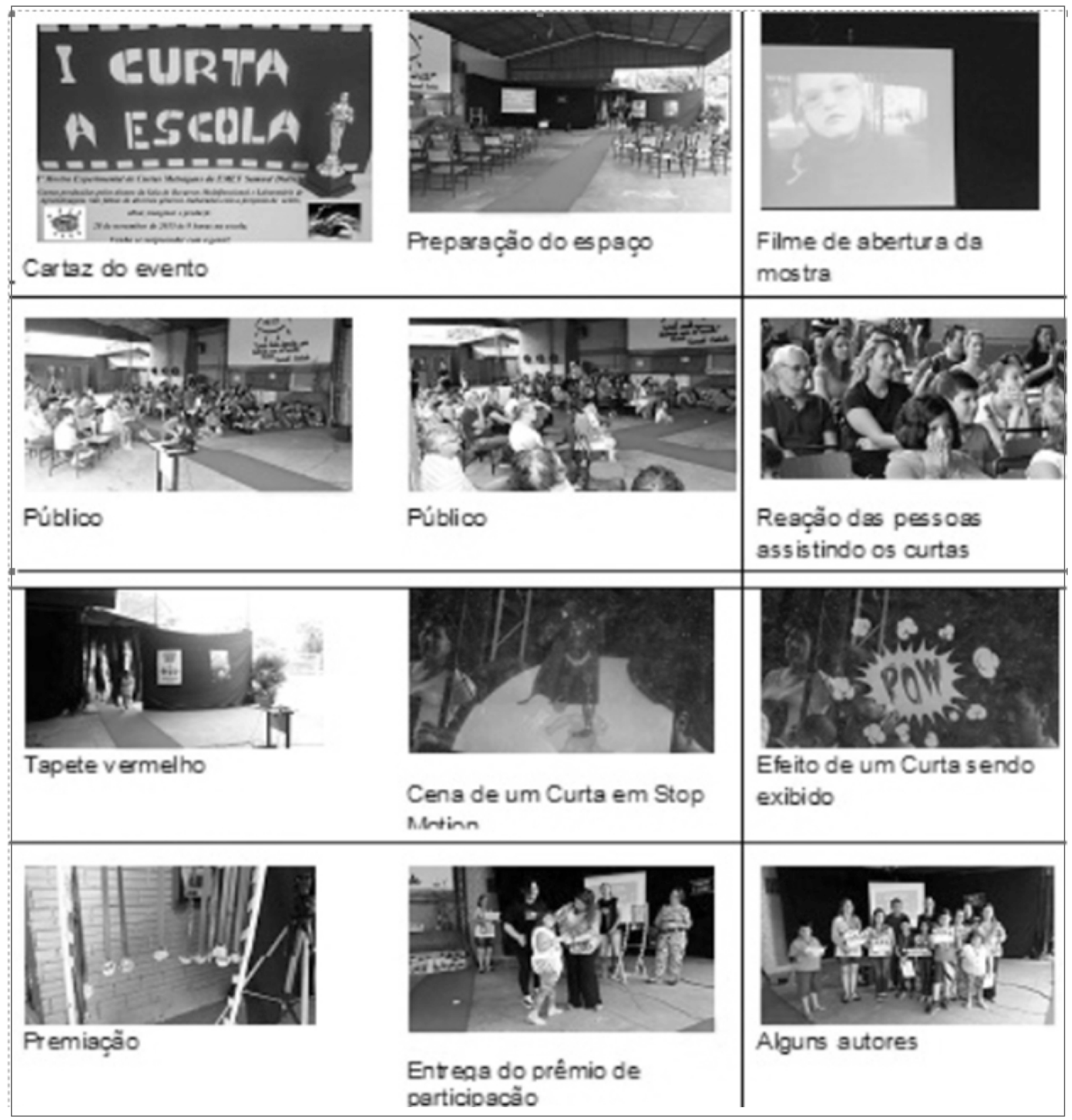

Figura 3. apresentação dos curtas metragens na escola. 


\section{CONSIDERAÇÕES FINAIS}

No início, quando se pensava no Grupo de Pesquisas ATRIUM em realizar esta intervenção nesta escola a partir do dispositivo cinematográfico, não se imaginou a proporção que ela atingiria. Alcançar os objetivos preestabelecidos foi somente uma das conquistas. A intervenção teve um 'ganho' muito maior. Foi muito além do esperado!

Os alunos sentiram-se mais seguros e valorizados, com isso melhoraram sua autoestima e aprendizagem. Quem já estava alfabético, conseguiu aprimorar as suas produções escritas, melhorando o vocabulário, trazendo uma melhor segmentação do texto em parágrafos e sequência lógica das ideias. Quem estava iniciando o processo de alfabetização também melhorou o seu desempenho. Já lê e escreve palavras simples.

Todos cresceram ao longo do processo. Destaca-se também, a mudança de postura dos alunos, que engloba vários aspectos como aprendizagem, interação com os colegas e o professor, a sensibilidade de ver o subjetivo e a melhora da autoestima.

Foi proposto a abordagem da língua tanto escrita quanto falada na educação formal quando se trabalhou a escrita na criação do roteiro e na pesquisa. A matemática na edição do filme quando se calculava com os alunos o tempo dos vídeos. Abordou-se o uso das ferramentas tecnológicas que trouxeram a vida para suas histórias. E muitos outros conhecimentos.... Os alunos e o Grupo de pesquisa, também, vivenciaram as questões que envolvem a educação informal, quando se permitiu que os alunos utilizassem os seus conhecimentos de mundo nos 'curtas' que produziram.

Acredita-se que a educação tem que ser atraente e que o processo de aprendizagem deve privilegiar ações em que os alunos são protagonistas, autores da sua própria aprendizagem. A produção de Curta
Metragem permite isso, porque é um processo rico em criação e desenvolve muitas outras habilidades que trazem os desejos à tona e oportuniza os alunos a aprenderem, pois os alunos se sentem motivados e valorizados pela sua produção.

Percebeu-se que a produção de curtas-metragens não se justifica apenas pelo resultado final, mas sim por todo processo percorrido pelos alunos ao longo das suas produções.

A experiência de produzir um Curta Metragem como estratégia de autoria, aprendizagem e inclusão pode ser utilizada por qualquer professor, independente da série e área que atua. É um processo simples de criação e pode ser feito com poucos recursos, utilizando uma máquina fotográfica e um computador. Porém, o mais importante é ter vontade de realizá-lo. Talvez a dificuldade maior seria de editar o vídeo, mas atualmente existem tutoriais na internet e programas que facilitam esse trabalho. Se os alunos se sentirem motivados e a relação for de interação entre todos os envolvidos no processo, os resultados serão superpositivos e a aprendizagem será uma consequência.

Atualmente, o "Curta a Escola» faz parte do calendário anual de atividades da escola e foi ampliado para todas as turmas! 


\section{Ingenierías: $:$.}

\section{REFERENCIAS}

Freire, P. (2003). Pedagogia da Esperança: um reencontro com a pedagogia do oprimido.. 11a ed. São Paulo: Paz e Terra .

González Rey, F. (2005). Pesquisa Qualitativa e Subjetividade: os processos de construção da informação. Trad. Marcel Aristides Ferrara Silva. São Paulo: Pioneira Thompson Learning.

Minayo de S. O, M. C. S. (2010). desafio do conhecimento: pesquisa qualitativa em Saúde. 12a Ed. São Paulo: Hucitec-Abrasco.

Moran, J. M. (1993). Leituras dos Meios de Comunicação. São Paulo: Ed. Pancast.

Pereira, J. \& Janhke, G. (2012). A produção de vídeo na escola Educar com Prazer. Estudo de caso. Escola Independência Pelotas. Pelotas: ERD Filmes.

Yin, R. K. (2003). Case study research, design and methods. 3rd ed. Newbury Park: Sage Publications. 